\title{
Detection of Biologically Active Adenovirions Unable to Plaque in Human Cells
}

\author{
JANET S. BUTEL, JOSEPH L. MELNICK, AND FRED RAPP \\ Department of Virology and Epidemiology, Baylor University College of Medicine, Houston, Texas
}

Received for publication 16 March 1966

\begin{abstract}
Butel, JANET S. (Baylor University College of Medicine, Houston, Tex.), JosePH L. MELNICK, AND FRED RAPP. Detection of biologically active adenovirions unable to plaque in human cells. J. Bacteriol. 92:433-438. 1966.-Plaque formation in green monkey kidney (GMK) cells by a defective simian virus 40-adenovirus 7 "hybrid" population (PARA-adenovirus 7) was enhanced by the addition of excess adenovirions. Adenovirus types 2, 7, and 12 were capable of providing enhancement, although none of these viruses gives rise to plaques in simian cells in the absence of PARA (particle aiding replication of adenovirus). Near maximal enhancement of the PARA plaque titer on simian cells was obtained with input multiplicities ranging from 0.02 to 0.14 plaque-forming units (PFU) of helper adenovirus per GMK cell. The PFU of helper adenoviruses tested (types 2, 7, and 12) were measured in the most sensitive assay system, human kidney cells. This input corresponded to three to nine helper virus particles per GMK cell. The majority of particles capable of enhancing plaque formation by PARA banded at a density of 1.34 in $\mathrm{CsCl}$. Adenoviruses inactivated by heat or ultraviolet light were not capable of enhancing plaque formation by PARA. Highest titers were obtained when PARA and helper adenovirus were inoculated simultaneously. Inoculation of the helper adenovirus $24 \mathrm{hr}$ prior to the inoculation of PARA resulted in the formation of only $50 \%$ as many plaques, and no enhanced plaques developed when the adenovirus preceded PARA by $48 \mathrm{hr}$. Conversely, the addition of adenovirus $48 \mathrm{hr}$ after the inoculation of PARA initiated $56 \%$ as many plaques as simultaneous inoculation; $4 \%$ of the enhanced plaques still formed when helper virus was added as late as 5 days after inoculation of PARA. These results suggest that adenovirus particles unable to plaque on human or monkey kidney cells are nevertheless capable of interacting with PARA in simian cells, thereby facilitating replication of both particles.
\end{abstract}

A simian virus 40 (SV40)-adenovirus type 7 "hybrid" population has been described $(11,22$, 24) which can induce the synthesis of SV40 tumor (T) antigen, but cannot induce cells to produce SV40 viral (V) antigen. The SV40 $T$ antigen synthesized in response to infection with the "hybrid" is immunologically indistinguishable from that present in SV40-transformed cells (1, $8,16,19)$ or from that synthesized during the early stages of the SV40 cytolytic cycle $(10,18$, 21, 26). All biological activities of the "hybrid" population are inhibited by neutralization of the virus with adenovirus type-specific antiserum (11, $20,22,24)$. ["Hybrid" is used in the sense that it is a stable virus population which possesses determinants of two distinct parental types but the coat protein of only one parent (the adenovirus) on all virions in the population. The term does not imply a direct interaction of the nucleic acids of the parental types.]

The interaction of two particles in the "hybrid" is required to initiate plaque formation in green monkey kidney cells $(3,25)$. One of the particles is an adenovirus; the second, termed PARA (20), is a genetically defective SV40 component encased in an adenovirus capsid. Neither PARA nor adenovirus in the hybrid population can replicate in green monkey kidney cells in the absence of the other (4). The "hybrid" virus should therefore be more correctly referred to as a PARA-adenovirus population. The mutual dependence between PARA and adenoviruses for growth and plaque formation in simian cells is believed to represent a form of complementation $(3,4)$.

Addition of a heterotypic adenovirus to simian 
cells infected with PARA-7 (PARA coated with adenovirus type 7 protein) results in an antigenic shift of the capsid protein of PARA from that of adenovirus 7 to that of the heterotypic adenovirus $(4,20,23)$. The term "transcapsidation" has been proposed to describe this conversion (20).

In the course of these studies, it was observed that the addition of excess amounts of adenovirus to a PARA-adenovirus 7 population enhanced the PARA plaque titer in simian cells by as much as 200 -fold $(4,20)$. This report will describe some of the novel quantitative characteristics of this enhancement phenomenon. In particular, it will show that many adenovirus particles unable to plaque on human cells are capable of interacting with PARA in simian cells to initiate plaque formation.

\section{Materials and Methods}

Cells. Primary cultures of African green monkey kidney (GMK) cells (Cercopithecus aethiops) were grown in lactalbumin hydrolysate (M-H) medium containing $2 \%$ calf serum and were maintained in serum-free M-E medium (14).

Human embryonic kidney (HEK) cells were grown in $\mathrm{M}$-H supplemented with $10 \%$ fetal bovine serum (FBS) and were maintained in M-H with $2 \%$ FBS.

Viruses. The history of the SV40-adenovirus type 7 "hybrid," stock SP2, has been previously described $(11,22,24)$. It was used after two additional passages in GMK cells. It will be referred to as PARA-adenovirus 7 . This virus stock contained infectious adenovirus 7 and PARA-7.

Adenovirus type 7 employed in this study was derived from the SP2 stock by Boeyé et al. (2). It was plaque-purified three times in HEK cells and found to be free from detectable SV40 determinants. Adenovirus type 2 was a recent human isolate supplied by $M$. Benyesh-Melnick and used after four passages in KB cells. Adenovirus type 12, originally obtained from R. J. Huebner, had undergone numerous passages in $\mathrm{KB}$ cells. It was passed once in HEK cells and then once again in KB cells. Both viruses were tested and found free from detectable SV40 determinants.

All virus stocks were prepared in cells growing in 16-oz bottles. Viruses were harvested by disrupting the cells into the medium with two cycles of quickfreezing and thawing, followed by treatment in a sonic oscillator. Cell debris was removed by low-speed centrifugation and the supernatant fluids were dispensed in 1-ml portions in glass ampoules. The ampoules were sealed, the contents were quick-frozen, and the ampoules were stored at $-90 \mathrm{C}$.

Antisera. Rabbits were used for the preparation of neutralizing antisera against the types 2,7 , and 12 adenoviruses described above. The animals received 1 intramuscular injection of $2 \mathrm{ml}$ of undiluted virus fluids weekly for 3 weeks, a fourth inoculation 2 weeks later, and were bled out 2 weeks after the final inoculation.

Virus assays. Plaque assays for adenoviruses in
HEK cells and for PARA in GMK cells have been described in detail $(2,4,6,20)$. Briefly, PARA titrations were routinely performed by co-infecting GMK monolayers in $60-\mathrm{mm}$ plates with a dilution of helper adenovirus which was not cytotoxic but yet provided a multiplicity of infection of about 1 plaque-forming unit (PFU)/cell, the PFU having been determined in human kidney cells. The helper virus and the PARA being assayed were allowed to adsorb simultaneously for 60 to $90 \mathrm{~min}$ at $37 \mathrm{C}$, at which time an agar overlay was applied. The overlay consisted of Eagle's medium, $10 \%$ FBS, $1 \%$ agar, and $0.23 \%$ sodium bicarbonate. A second overlay containing a 1:20,000 dilution of neutral red was applied 1 week later. Plaques were visible the following day, but maximal titers generally were not reached until the 4th day after the second overlay was applied. Adenoviruses were titrated in HEK cells with the use of the same overlay. All assays employed two or three plates per dilution.

Inactivation techniques. Heat inactivation was accomplished by placing small portions of the virus suspensions in stoppered, thin-walled glass tubes, and heating for $45 \mathrm{~min}$ in a water bath at $50 \mathrm{C}$.

Ultraviolet (UV) light inactivation was carried out with a Westinghouse Sterilamp 615 T3. Virus suspensions were sonically treated prior to exposure to UV to dissociate aggregates. Amounts of $1 \mathrm{ml}$ of the sonically treated suspensions were placed in $60-\mathrm{mm}$ plastic petri dishes and irradiated for $5 \mathrm{~min}$. The tops of the plates were removed, and the contents were swirled continuously during the exposure period. All work with UV-irradiated virus was carried out in a darkened room to exclude photoreactivation.

Particle counts. The pseudoreplication and staining methods described by Smith and Melnick (27) were used to prepare specimens for viewing with a Hitachi HU-11B electron microscope.

Density gradient centrifugation. Adenovirus was banded in a preformed gradient of cesium chloride (CsCl) by centrifugation at $39,000 \mathrm{rev} / \mathrm{min}$ for $18 \mathrm{hr}$ at $4 \mathrm{C}$ in a Spinco model $\mathrm{L} 2$ centrifuge with an SW$39 \mathrm{~L} 2$ rotor. Samples were collected in droplets from the bottom of the tube, the refractive indices of the fractions were determined in a Bausch and Lomb refractometer, and these values were converted to buoyant density.

\section{RESULTS}

Enhancement by adenoviruses of plaque formation by PARA in simian cells. Many human adenoviruses do not replicate in GMK cells in the absence of SV40 $(4,5,6,17)$. When high concentrations of such adenoviruses are added to monolayers of GMK cells, the plaque titer of the PARA-adenovirus 7 stock is enhanced by as much as 200 -fold $(4,20)$. In recent experiments with the virus stocks used for the present work, the PARAadenovirus 7 titer increased from $10^{4.9}$ to $10^{6.4}$ and $10^{6.5} \mathrm{PFU} / \mathrm{ml}$ in the presence of additional adenovirus type 7 or type 2 , respectively. Adenovirus type 12 enhanced the titer of the PARAadenovirus 7 stock from $10^{4.5}$ to $10^{6.3} \mathrm{PFU} / \mathrm{ml}$. 
Thus, it was confirmed that heterotypic adenovirus types 2 and 12 enhanced PARA-adenovirus 7 plaque titers as effectively as the homologous type 7.

Enhancement as a function of the concentration of helper adenovirus. Various dilutions of each helper adenovirus were inoculated onto replicate GMK monolayers, and the degree of enhancement of the PARA plaque titer was calculated. Close to maximal enhancement, over 20 times, was already obtained with multiplicities of infection ranging from 0.02 to 0.14 PFU of helper virus per cell (Fig. 1); the PFU values again, by necessity, had to be determined in HEK cells. These values were obtained with preparations of adenovirus types 2 and 12, respectively. Adenovirus type 7 yielded an intermediate value of 0.09 PFU per cell.

Particle counts were performed on the adenovirus preparations (electron microscopy was performed by Robert Rongey). The number of particles per PFU varied from 32 to 217 (Table 1). Based on these particle counts, essentially maximal enhancement was obtained in the nar-

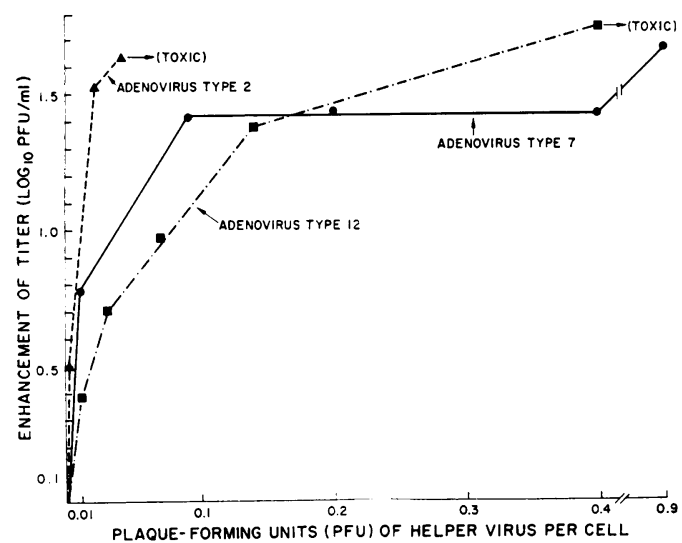

FIG. 1. Effect of concentration of plaque-forming units of helper adenovirus on plaque formation by $P A R A$ in simian cells.

TABle 1. Particles to plaque-forming units $(P F U)$ in the helper adenovirus preparations

\begin{tabular}{c|c|c|c}
\hline Helper virus & $\begin{array}{c}\text { Particle count } \\
\text { (particles/ml })\end{array}$ & $\begin{array}{c}\text { Titer } \\
(\mathrm{PFU} / \mathrm{ml})\end{array}$ & $\begin{array}{c}\text { Particles } \\
\text { per PFU }\end{array}$ \\
\cline { 2 - 3 } $\begin{array}{c}\text { Adenovirus } \\
\text { type 7 }\end{array}$ & $5.5 \times 10^{9}$ & $1.7 \times 10^{8}$ & 32 \\
$\begin{array}{c}\text { Adenovirus } \\
\text { type 12 }\end{array}$ & $1.9 \times 10^{9}$ & $2.8 \times 10^{7}$ & 68 \\
$\begin{array}{c}\text { Adenovirus } \\
\text { type 2 }\end{array}$ & $7.6 \times 10^{9}$ & $3.5 \times 10^{7}$ & 217 \\
\hline
\end{tabular}

row range of an input of three to nine particles of helper virus per cell (Fig. 2). The minimal number of particles required for near maximal enhancement by the different helper viruses tested were specifically: three in the case of adenovirus 7 ; four with adenovirus 2 ; and nine particles per cell with adenovirus 12 .

The helper adenovirus type 7 was centrifuged in cesium chloride, and fractions at different densities were analyzed for ability to enhance plaque formation by PARA in GMK cells. As seen in Fig. 3, most of the activity was with virus having a buoyant density of 1.34 ; it is this virus that carries the bulk of adenovirus infectivity as measured in HEK cells. It should be noted that none of the helper adenovirus stocks contained the recently described adeno-satellite virus (13).

Effect on enhancement of time of addition of helper adenovirus. Routinely, the PARA-adenovirus 7 and helper adenovirus were inoculated onto GMK monolayers and allowed to adsorb simultaneously. Experiments were carried out to

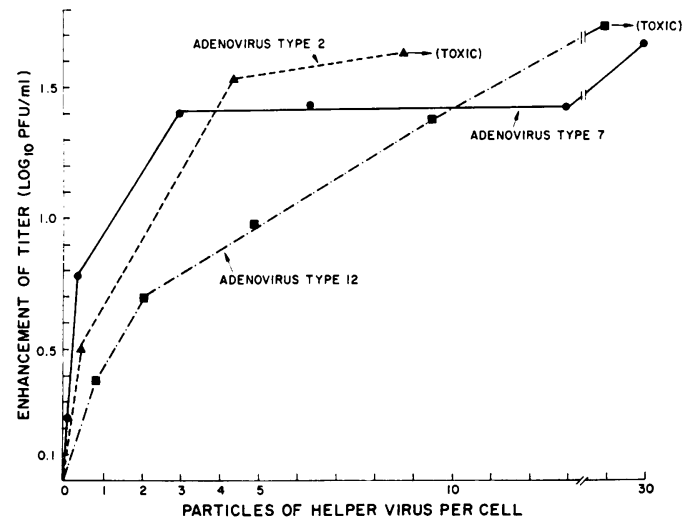

FIG. 2. Effect of concentration of particles of helper adenovirus on plaque formation by PARA in simian cells.

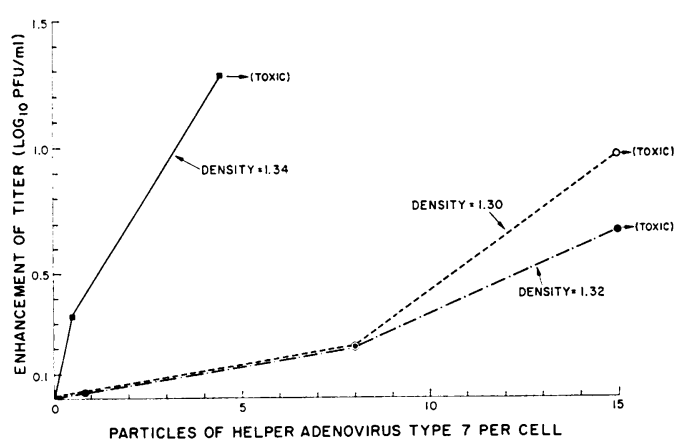

F1G. 3. Ability of adenovirus particles with various densities to enhance plaque formation by PARA in simian cells. 
determine the optimal time of addition of the helper virus. GMK monolayers were inoculated with helper adenovirus either before or after inoculation with PARA. PARA was inoculated by use of a $10^{-4}$ dilution of the PARA-adenovirus 7 stock, as at this dilution no plaques formed in the absence of enhancement by an adenovirus. Inoculated monolayers were held under fluid medium until the second virus was added, at which time an agar overlay was applied. Control monolayers were inoculated with both PARA and adenovirus each day to control any variation in cell susceptibility due to aging. As can be seen in Fig. 4 (left side), only $50 \%$ as many enhanced plaques were obtained when the adenovirus was inoculated $24 \mathrm{hr}$ before PARA as compared with titers obtained when the viruses were inoculated together. No enhanced plaques were formed when the helper adenovirus was inoculated $48 \mathrm{hr}$ before PARA.

Titers dropped less rapidly when adenovirus was inoculated after PARA: $56 \%$ of the enhanced plaques developed when the adenovirus was inoculated $48 \mathrm{hr}$ after inoculation of PARA; $4 \%$ of the enhanced plaques still formed when helper adenovirus was added as late as 5 days after PARA (Fig. 4, right side). Similar results were obtained in two additional tests.

Inactivation of ability of adenovirus to enhance plaque formation by $P A R A$. As expected, the infectivity of helper adenoviruses was inactivated by treatment with either heat or UV light. These inactivated adenoviruses were no longer capable of enhancing plaque formation in GMK cells by PARA (Table 2). The untreated adenovirus type $7 \mathrm{had}$ an initial titer of $10^{8.3} \mathrm{PFU} / \mathrm{ml}$ on HEK cells, and enhanced plaque formation by the PARA-adenovirus population 25-fold. After treatment with heat or UV light, the adenovirus 7 titer was reduced to $10^{4.3}$ and $10^{4.7} \mathrm{PFU} / \mathrm{ml}$,

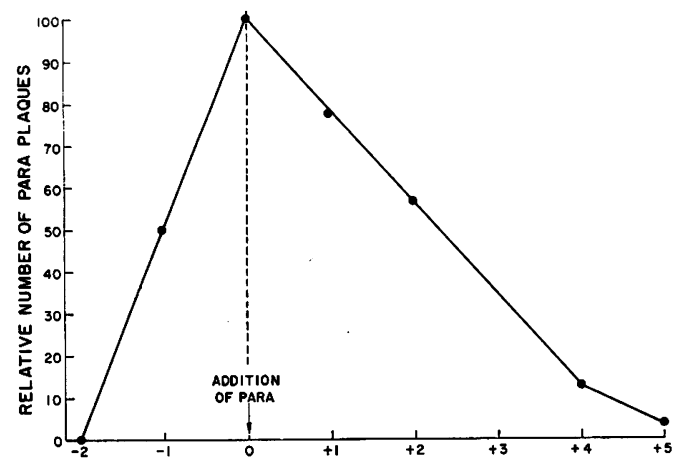

DAY ON WHICH HELPER ADENOVIRUS TYPE 7 WAS ADDED

FIG. 4. Effect of time of addition of helper adenovirus on plaque formation by PARA in simian cells.
TABLE 2. Failure of adenovirus inactivated by heat or ultraviolet light to enhance plaque formation by $P A R A$

\begin{tabular}{|c|c|c|c|c|}
\hline $\begin{array}{l}\text { Enhancing } \\
\text { adenovirus }\end{array}$ & $\begin{array}{c}\text { Treatment } \\
\text { of enhanc- } \\
\text { ing adeno- } \\
\text { virus }\end{array}$ & $\begin{array}{l}\text { Titer of } \\
\text { enhancing } \\
\text { adenovirus } \\
\text { on HEK } \\
\text { cells (log } 10 \\
\text { PFU/ml) }\end{array}$ & $\begin{array}{l}\text { Titer of } \\
\text { PARA-adeno- } \\
\text { virug } 7 \text { stock } \\
\text { on GMK cells } \\
\text { (log } 10 \mathrm{PFU} / \mathrm{ml})\end{array}$ & $\begin{array}{c}\text { Enhance- } \\
\text { ment of } \\
\text { PARA }\end{array}$ \\
\hline None & & & 4.9 & \\
\hline Type 7 & None & 8.3 & 6.3 & 25 -fold \\
\hline Type 7 & Heat $^{a}$ & 4.3 & 4.8 & None \\
\hline Type 7 & $\mathbf{U V}^{b}$ & 4.7 & 4.8 & None \\
\hline Type 2 & None & 7.8 & 6.9 & 100 -fold \\
\hline Type 2 & Heat ${ }^{a}$ & 5.2 & 4.9 & None \\
\hline Type 2 & $\mathbf{U V}^{b}$ & 4.6 & 4.8 & None \\
\hline
\end{tabular}

${ }^{a}$ For $45 \mathrm{~min}$ at $50 \mathrm{C}$.

${ }^{b}$ Exposed for $5 \mathrm{~min}$.

respectively. These preparations, even though not completely inactivated, were not able to enhance plaque formation by PARA-adenovirus 7 . As can also be seen in Table 2, very similar results were obtained with adenovirus type 2 .

\section{Discussion}

Results presented previously $(3,4,20)$ and in this paper show that the addition of high concentrations of noncytopathic adenovirions enhances plaque formation in simian cells by a defective SV40-adenovirus population (termed PARAadenovirus). The enhancement is possible because PARA is unable to replicate unless a coinfecting adenovirus is present to provide the coat protein for PARA $(4,20,23)$. Enhancement is not restricted to the homologous adenovirus type 7 but can also be demonstrated with the heterotypic types $2,4,5$, and $12(4,20,23)$ and with types 3,6, 16, and 21 (Rapp, unpublished data). It is not surprising that heterotypic adenoviruses are capable of interacting with PARA since it has been shown that complete SV40 will react in adenovirus-infected cells and potentiate the replication of adenovirus types 2, 5, 7, and 12 in GMK cells $(4,5,6,15,17)$.

Maximal enhancement is obtained with an input of between 3 and 9 helper virus particles per cell. These values hold even for populations in which only one of every 217 particles plaques as an infective unit on HEK cells, the most sensitive bioassay system known for human adenoviruses. Essentially maximal enhancement was already obtained with inputs ranging from 0.02 to 0.14 PFU (as determined in HEK cells) of helper virus per GMK cell; additional adenovirus did not substantially increase titers of the PARA virus. 
Adeno-satellite virus (13) was not present in any stocks and could not be an essential factor.

The explanation for the requirement of less than 1 PFU, as measured in HEK cells, of adenovirus per GMK cell to obtain maximal enhancement of PARA is not known. It is possible that many adenovirions in the population are biologically active in regard to certain functions (perhaps enzyme induction) but cannot plaque even on the sensitive HEK cells. This hypothesis is somewhat supported by Wasserman's (28) observation that adenovirions are not uncoated efficiently in human cells, but the hypothesis requires the unproven assumption that uncoating (but not subsequent replication) of adenoviruses in simian cells is more efficient than in human cells.

An alternate explanation would be that many of these adenovirus particles contain incomplete nucleic acid complements and that PARA is supplying needed adenovirus information. Somewhat analogous are the observations made with two plant viruses (29). The addition of a noninfectious "middle" component (obtained by centrifugation) to the "bottom" component increased the infectivity of the latter. The "top" component which contains no ribonucleic acid (RNA) had no such enhancing effect. It was suggested by the authors that perhaps some of the RNA in the "bottom" component had been rendered noninfectious in such a way as to allow activation by the incomplete RNA from the "middle" component. However, it is not yet known whether PARA contains any adenovirus nucleic acid in addition to the defective portion of SV40 deoxyribonucleic acid (DNA). Experiments are currently in progress to test this hypothesis.

Fenner and Sambrook (7), in reviewing experiments of phenotypic mixing, suggested that some noninfectious particles in a virus stock can contribute to the total virus yield, at least in cells in which an infective particle is multiplying. This conclusion was based on data obtained by Ledinko and Hirst (12) with poliovirus and by Granoff (9) with Newcastle disease virus. Our results are compatible with this suggestion, but the data thus far available do not allow resolution of the alternate hypotheses discussed above. However, it is clear that the system being studied is a more sensitive measure for infectivity of adenoviruses than the plaque assay in HEK cells, hitherto regarded as the most sensitive system for adenoviruses.

\section{ACKNOWLEDGMENTS}

This investigation was supported by Public Health Service grants CA-04600 from the National Cancer
Institute and $\mathrm{AI} 05382$ and $5 \mathrm{T1} \mathrm{AI} 74$ from the National Institute of Allergy and Infectious Diseases.

\section{Literature Cited}

1. Black, P. H., W. P. Rowe, H. C. Turner, AND R. J. Huebner. 1963. A specific complementfixing antigen present in SV40 tumor and transformed cells. Proc. Natl. Acad. Sci. U.S. 50: $1148-1156$

2. Boeyé, A., J. L. Melnick, and F. Rapp. 1965. Adenovirus-SV40 "hybrids:" plaque purification into lines in which the determinant for the SV40 tumor antigen is lost or retained. Virology 26:511-512.

3. Boeyé, A., J. L. Melnick, and F. Rapp. 1966. SV40-adenovirus "hybrids:" Presence of two genotypes and the requirement of their complementation for viral replication. Virology 28:56-70.

4. BuTEL, J. S., AND F. RAPP. 1966. Replication in simian cells of defective viruses in an SV40adenovirus "hybrid" population. J. Bacteriol. 91:278-284.

5. Feldman, L. A., J. S. Butel, and F. Rapp. 1966. Interaction of a simian papovavirus and adenoviruses. I. Induction of adenovirus tumor antigen during abortive infection of simian cells. $J$. Bacteriol. 91:813-818.

6. Feldman, L. A., J. L. Melnick, and F. Rapp. 1965. Influence of SV40 genome on the replication of an adenovirus-SV40 "hybrid" population. J. Bacteriol. 90:778-782.

7. Fenner, F., and J. F. Sambrook. 1964. The genetics of animal viruses. Ann. Rev. Microbiol. 18:47-94.

8. Gilden, R. V., R. I. CarP, F. TAGUCHI, and V. DEFENDI. 1965. The nature and localization of the SV40-induced complement-fixing antigen. Proc. Natl. Acad. Sci. U.S. 53:684-692.

9. Granoff, A. 1961. Studies on mixed infection with Newcastle disease virus. III. Activation of nonplaque-forming virus by plaque-forming virus. Virology 14:143-144.

10. Hoggan, M. D., W. P. Rowe, P. H. BLACK, AND R. J. HuebNer. 1965. Production of "tumorspecific" antigens by oncogenic viruses during acute cytolytic infections. Proc. Natl. Acad. Sci. U.S. 53:12-19.

11. Huebner, R. J., R. M. Chanock, B. A. Rubin, AND M. J. CASEY. 1964. Induction by adenovirus type 7 of tumors in hamsters having the antigenic characteristics of SV40 virus. Proc. Natl. Acad. Sci. U.S. 52:1333-1340.

12. LedinKo, N., AND G. K. Hirsi. 1961. Mixed infection of HeLa cells with polioviruses types 1 and 2. Virology 14:207-219.

13. Melnick, J. L., H. D. Mayor, K. O. SMith, AND F. RAPP. 1965. Association of 20-millimicron particles with adenoviruses. J. Bacteriol. 90: 271-274.

14. Melnick, J. L., H. A. Wenner, And L. Rosen. 1964. The enteroviruses, p. 194-242. In E. H. Lennette and N. J. Schmidt [ed.], Diagnostic procedures for viral and rickettsial diseases, 
3rd ed. American Public Health Association, Inc., New York.

15. O'Conor, G. T., A. S. Rabson, I. K. Berezesky, AND F. J. PAUL. 1963. Mixed infection with simian virus 40 and adenovirus 12. J. Natl. Cancer Inst. 31:903-917.

16. PoPe, J. H., AND W. P. Rowe. 1964. Detection of specific antigen in SV40-transformed cells by immunofluorescence. J. Exptl. Med. 120:121128.

17. Rabson, A. S., G. T. O'Conor, I. K. Berezesky, AND F. J. PAUL. 1964. Enhancement of adenovirus growth in African green monkey kidney cell cultures by SV40. Proc. Soc. Exptl. Biol. Med. 116:187-190.

18. Rapp, F., J. S. Butel, L. A. Feldman, T. KitaHARA, AND J. L. Melnick. 1965. Differential effects of inhibitors on the steps leading to the formation of SV40 tumor and virus antigens. J. Exptl. Med. 121:935-944.

19. Rapp, F., J. S. Butel, AND J. L. Melnick. 1964. Virus-induced intranuclear antigen in cells transformed by papovavirus. SV40. Proc. Soc. Exptl. Biol. Med. 116:1131-1135.

20. Rapp, F., J. S. Butel, AND J. L. MelniCK. 1965. SV40-adenovirus "hybrid" populations: Transfer of SV40 determinants from one type of adenovirus to another. Proc. Natl. Acad. Sci. U.S. 54:717-724.

21. Rapp, F., T. Kitahara, J. S. Butel, AND J. L. MELNICK. 1964. Synthesis of SV40 tumor antigen during replication of simian papovavirus
(SV40). Proc. Natl. Acad. Sci. U.S. 52:11381142.

22. Rapp, F., J. L. Melnick, J. S. Butel, and T KitahaRA. 1964. The incorporation of SV40 genetic material into adenovirus 7 as measured by intranuclear synthesis of SV40 tumor antigen. Proc. Natl. Acad. Sci. U.S. 52:1348-1352.

23. Rowe, W. P. 1965. Studies of adenovirus SV40 hybrid viruses. III. Transfer of SV40 gene between adenovirus types. Proc. Natl. Acad. Sci. U.S. 54:711-717.

24. Rowe, W. P., and S. G. Baum. 1964. Evidence for a possible genetic hybrid between adenovirus type 7 and SV40 viruses. Proc. Natl. Acad. Sci. U.S. 52:1340-1347.

25. Rowe, W. P., AND S. G. Baum. 1965. Studies of adenovirus SV40 hybrid viruses. II. Defectiveness of the hybrid particles. J. Exptl. Med. 122:955-966.

26. SABIN, A. B., AND M. A. Кoch. 1964. Source of genetic information for specific complementfixing antigens in SV40 virus-induced tumors. Proc. Natl. Acad. Sci. U.S. 52:1131-1138.

27. Smith, K. O., AND J. L. MelNiCK. 1962. A method for staining virus particles and identifying their nucleic acid type in the electron microscope. Virology 17:480-490.

28. WASSERMANN, F. E. 1965. The effect of UV-radiation on HeLa cells infected with adenovirus. Virology 27:193-198.

29. WoOd, H. A., AND J. B. BANCROFT. 1965. Activation of a plant virus by related incomplete nucleoprotein particles. Virology 27:94-102. 